\title{
El "impulso" en psicoanálisis y conceptos afines en filosofía analítica de la mente*
}

\author{
Carlos de la Puente
}

Universidad de Lima

Recibido: 7 de julio del 2011 / Aprobado: 25 de julio del 2011

En este artículo se analizan las definiciones sobre el concepto de instinto que se encuentran en la obra de Freud y se señala la tensión que existe, dentro de esta obra, entre una definición más fenomenológica y otra de corte más biológico. Se discuten las controversias que sobre este concepto ha tenido lugar en la literatura posfreudiana y se examinan brevemente algunos argumentos, provenientes de la filosofía, para criticar la versión biologista. Apoyado en el trabajo de un psicoanalista de la escuela de las relaciones objetales, el autor concluye que llamamos instintos a un conjunto de conductas que el ser humano aprende y desarrolla a lo largo de su vida.

\section{impulso / psicoanálisis / filosofía de la mente}

The concept of "impulse" in psychoanalysis and related concepts in analytic philosophy of mind

The different definitions of the concept of instinct within psychoanalytic theory are discussed in this article, highlighting the tension that exists in Freud' writings between a more phenomenological version of instinct, or drive, and a concept with biological overtones. The controversies around this concept are discussed and arguments stemming from philosophy against the biological version are considered. Relying on the work of a psychoanalyst from the object relations theory, the author concludes that psychoanalysis should overcome a body based notion of instinct and consider it instead as a behavior that human beings learn in the course of their interactions.

impulse / psychoanalysis / philosophy of mind

\footnotetext{
* Este trabajo es parte de una investigación que estoy realizando con el apoyo del Instituto de Investigación Científica de la Universidad de Lima. Agradezco a Marga Stahr, de la Sociedad Peruana de Psicoanálisis, por sus útiles comentarios a una primera versión de este artículo.

Correo electrónico: capuente@ulima.edu.pe
} 
Una de las ideas que Wittgenstein atacó con más denuedo en sus Investigaciones filosóficas es esta: dado que los seres humanos aprendemos a hablar conectando directamente las cosas que vemos con palabras que designan esas cosas, entonces el lenguaje debe funcionar así, "en una sola vía": de un lado los objetos y del otro las palabras que designan estos objetos. El significado de las palabras se explicaría, de acuerdo con esta concepción, a través de definiciones "ostensivas", definiciones que conectan de este modo unilateral a las palabras con las cosas.

El ataque, victorioso podríamos decir, contra la idea de que el significado de una palabra se explica a través de definiciones ostensivas ha tenido una influencia grande no solo en la filosofía del lenguaje sino también en las teorías psicológicas. Buena parte de los que escriben artículos y libros en el campo de la filosofía psicológica rechazan hoy, gracias en buena medida a Wittgenstein, la idea de que la mente está poblada por objetos que designamos ostensivamente objetos, que por añadidura serían "privados". Lo que obliga a preguntarse ¿qué influencia ha tenido esta suerte de pequeña revolución en la comprensión de lo mental en la psicología académica? En el caso del psicoanálisis, sostengo que Freud estuvo a punto de empezar a transitar el camino del Wittgenstein cuando, en 1897, es decir mucho antes de la aparición de las Investigaciones filosóficas le comunicó a su amigo Fliess (Freud, 1950) que sus pacientes histéricas no necesariamente habían sufrido las agresiones sexuales que contaban en sus consultas, agresiones que Freud pensaba eran la causa de sus síntomas histéricos, sino que solo habían fantaseado tal intento de seducción. Digo que Freud estuvo a punto de empezar a transitar el camino que trazaría muchos años después Wittgenstein porque lo que en verdad pudo descubrir Freud a través de este hallazgo es que el uso correcto de una expresión lingüística (en este caso las palabras relacionadas con la seducción y el deseo sexual) no se aprende únicamente a través de una demostración ostensiva y por lo tanto el significado de una expresión no se explica con una definición ostensiva. Pero Freud no siguió este camino, que quizá lo hubiera llevado a una concepción menos naturalista de la mente. Como es sabido, sostuvo que una fantasía sexual -y no la memoria reprimida de un hecho real- era el origen de la enfermedad de sus pacientes, pero concibió "fantasía" solo en términos de un imaginarse icónicamente que ocurre "dentro" de la cabeza, con lo que situó su teoría más cerca de esa visión de la mente que Wittgenstein y sus seguidores se han encargado de demoler: la de un escenario poblado de objetos internos y privados.

La obra de Freud creció y se desarrolló flanqueada por las miradas críticas de, por un lado, la filosofía analítica de la mente inspirada en los escritos de 
Wittgenstein, y, por el otro, por la fenomenología, sobre todo de Merleau Ponty, escuelas ambas que coincidieron en demandarle al psicoanálisis que se alejara de esta concepción naturalista de lo mental mencionada líneas arriba. Y los escritos de Freud parecieron a veces, como cuando abandonó la teoría de la seducción, ceder a esta demanda. Se trató en verdad de un sutil movimiento pendular: las ideas de Freud a veces amagan acercarse a las de sus críticos anglosajones y continentales, para regresar, y quedarse, en el ámbito de postulados más "cientificistas".

Este sutil movimiento pendular, esta tensión que existe en la teoría psicoanalítica de la mente, se manifestó de un modo más evidente en el desarrollo de un concepto medular en la historia del psicoanálisis que es el concepto de pulsión o instinto, sobre el cual trata este ensayo. Como han señalado varios comentaristas, Freud no tuvo una visión estable del concepto de pulsión. Ese péndulo lo llevó a veces a concebirla en términos más teleológicos, vinculándola al significado de las conductas y otras veces en términos más biológicos. Y así como Freud, psicoanalistas y amigos del psicoanálisis optaron, en relación con la pulsión, ya por una comprensión más fenomenológica o por una más biológica. En este trabajo quiero explorar esta tensión en la definición de la pulsión psicoanalítica. Quiero también defender la idea de que la tentación biologizante debe ser su- perada en el psicoanálisis y que es la teoría de las relaciones objetales la que más ha hecho en ese sentido. Procederé, primero, a reseñar las dos definiciones que sobre pulsión dio Freud. Luego repasaré los argumentos de quienes criticaron la visión naturalista del instinto freudiano y de quienes la defendieron y la defienden, y finalmente, a manera de conclusión, bosquejaré una definición de pulsión.

\section{FREUD Y EL TERRENO DESCONOCIDO DE LA PULSIÓN}

Se ha dicho (Whitebook, 1994) que como el concepto de pulsión hace referencia a una realidad que está en la frontera de lo psíquico y de lo biológico, del cuerpo y de lo mental, Freud utilizó un vocabulario muy raro para referirse a ella: Repräsentanz, Vorstellung, Vorstellungsrepräsentanz, Triebrepräsentanz y sychischerepräsentanz son todas palabras que se yuxtaponen y a veces son confundidas por el mismo Freud. Por esta misma razón, es decir por la dificultad de la tarea, se cree que Freud se contradijo en cuanto a la naturaleza de la pulsión y hacia el final de su obra estipuló que era una de las regiones más enigmáticas del pensamiento psicoanalítico. ¿Cómo debemos entender hoy la naturaleza fronteriza de la pulsión? ¿Qué razones tendríamos hoy para aceptar que la pulsión alude al límite de lo corporal con lo mental y que, por lo tanto, la indagación acerca 
de la pulsión -hecha por supuesto con los recursos de lo mental- enfrenta barreras insuperables? En efecto, Freud afirmó más de una vez a lo largo de su obra que la idea de pulsión o el instinto ${ }^{1}$ se "nos aparece como un concepto fronterizo entre lo anímico y lo somático" (Freud 1915a). Esta aseveración, que sitúa la idea de instinto en verdad más cerca de lo somático que de lo anímico, ha estimulado la imaginación y la creatividad de los psicoanalistas, quienes - usando esa ubicación fronteriza de la pulsión como una premisaconjeturaron causas de enfermedades, formularon una teoría de la mente y hasta propusieron recomendaciones terapéuticas. $\mathrm{Y}$ es que las fronteras en general aluden casi siempre a lo inexplorado. Los límites del mundo han sido siempre terreno fértil para la fantasía y el mito. En distintas disciplinas el ser humano ha tratado lo fronterizo como aquello fascinante que no se conoce y que no es posible conocer. $\mathrm{Y}$ ha pasado lo mismo con el concepto de pulsión. Algunos psicoanalistas (Whitebook, 1994), partiendo de esta localización en el borde de lo mental y lo corporal, han defendido la idea de que al hablar de inconsciente y de pulsión estamos en el terreno de lo inefable. Es decir, en el dominio de las imágenes y no de las palabras. De manera que nuestros recursos conceptuales solo sirven para elabo-

1 La Stantard Edition de James Strachey traduce el término alemán Trieb por el de "Instinct". rar metáforas, en el mejor de los casos, sobre la esencia de la pulsión. Otros psicoanalistas, apoyados en esta característica fronteriza han terminando endosando el mito del "fantasma dentro de la máquina" mordazmente denunciado por Gilbert Ryle, al postular una especie de tercera dimensión ontológica, que no es ni física ni mental, es decir que no responde a las leyes físicas ni a los juegos de lenguaje del deseo o de la creencia. Freud mismo pensaba que un aura de misterio rodeaba al concepto de pulsión pero hay algunas indicaciones en el sentido de que él pensaba que el misterio se disiparía cuando avanzaran nuestros conocimientos sobre psicología y neurociencias.

Sin embargo, a renglón seguido de aquella frase famosa en la que aludió a la naturaleza fronteriza de la pulsión, Freud la define en términos mucho más psicológicos que físicos y señala que esta (i.e. la pulsión) es:

[...] un representante psíquico de los estímulos que provienen del interior del cuerpo y alcanzan el alma (la pulsión se nos presenta como) una medida de la exigencia de trabajo que es impuesta a lo anímico como consecuencia de su trabazón con lo corporal (Freud, 1915a, p. 117).

El instinto como representante psíquico es el argumento más recurrido por quienes quieren situar el psicoanálisis bajo el ámbito de una disciplina interpretativa. 
Pero esa no sería la única postura del creador del psicoanálisis acerca del instinto. El mismo año, en el tercer capítulo del ensayo Lo inconsciente (1915b), Freud ofreció una segunda definición de la pulsión que claramente contradice la que acabamos de citar porque se afirma más bien que de la pulsión solo podemos conocer sus derivados, es decir sus representantes psíquicos. La pulsión nunca se da a conocer: una pulsión nunca puede pasar a ser objeto de la conciencia; solo puede serlo la representación, que es su representante. Ahora bien, tampoco en el interior del inconsciente puede estar representada si no es por la representación. Si la pulsión no se adhiriera a una representación ni saliera a la luz como un estado afectivo nada podríamos saber de ella (Freud, 1915b, p. 173).

En esta segunda definición no pueden haber dudas de que Freud, al hablar de una pulsión que es incognoscible, distingue pulsión de representación. La pulsión propiamente dicha pertenecería a lo somático y su representante psíquico a lo psicológico.

Una pregunta que surge ante esta segunda definición freudiana es ¿cómo hablar de lo que es somático? ¿Cómo acercarnos con palabras y conceptos a lo que es, o sería, una manifestación de la naturaleza? Y si la pulsión pertenece a la región de lo indecible, si, como dice Freud, de ella solo conocemos sus derivados, entonces la pulsión es una realidad ontológica previa e independiente del sentido, de los significados socialmente compartidos. Habría entonces, de acuerdo con esta formulación de Freud, dos mundos de lo humano. El mundo que pertenece al cuerpo, a la energía psíquica, a los factores económicos de la conducta de los que habló Freud, y habría también el mundo de los conceptos, del yo, de las prácticas culturales, en una palabra del sentido que le damos a las cosas. Los escritos posteriores de Freud sugieren que esta concepción de la pulsión como biológica y conocible solo a través de sus derivados es la que deberíamos considerar como la versión oficial del pensamiento freudiano. En un trabajo posterior muy importante, El yo y el ello (1923), hablando del inconsciente y de las "sensaciones inconscientes", Freud suscribe la idea de que existe un "algo" psíquico que es anterior al lenguaje y que no necesita de las palabras para hacerse conscientes, con lo que está afirmando una región de lo mental que es totalmente interna, subjetiva y prelingüística. Son dos maneras diferentes de entender la pulsión, y siendo la pulsión un concepto troncal en la teoría psicoanalítica, cada una de ellas apunta a una posición epistemológica distinta. Si el instinto tiene un pie bien plantado en la Biología, entonces el psicoanálisis parece tener su hogar epistemológico en las ciencias naturales. Si, en cambio, el concepto de pulsión no se puede entender sin referirse al significado de la conducta entonces el psicoanálisis debería situarse 
en la provincia de la interpretación y de la hermenéutica. La controversia en relación con la naturaleza de la pulsión está muy vinculada a la discusión sobre dónde situar epistemológicamente al psicoanálisis.

Aunque ambas definiciones de pulsión han generado controversia, es particularmente la segunda la que ha causado las mayores confusiones y motivado las versiones del psicoanálisis más regresivas y con menos asiento científico. Al relegar a la pulsión a la categoría de lo incognoscible y al mismo tiempo otorgarle una influencia en la conducta, Freud abrió el camino para alejar al psicoanálisis del rigor conceptual y científico. Tan solo por esto: se trata de una conceptualización biologista de la pulsión que sin embargo no tiene cabida en la Biología contemporánea.

Ni la oscuridad que rodeó los esfuerzos de Freud por encontrar una definición de pulsión ni la cantidad y variedad de palabras con las que intentó completar esta tarea debe, sin embargo, impedirnos clarificar lo que significó la pulsión en los escritos freudianos. En resumidas cuentas, Freud consideró que hay dos o tres cosas esenciales en la pulsión: una idea o una representación (que coincide con la intención, en el sentido no técnico de esta palabra), un monto de afecto, y si se quiere aceptar la tesis biologista de una pulsión escondida en lo más profundo de la mente (la tesis que Freud defendió en Lo inconsciente) y una pulsión propiamente dicha de lo que solo conocemos sus derivados. Quizá haya espacio para pensar, siempre de acuerdo con Freud, en una especie de vivencia precognitiva de la pulsión, algo entre la idea (Vorstellung) y el afecto y esto quizá sería parte del "representante-representativo". Pero creo que es contraproducente (además de mistificador) asumir esta postura, que es en verdad consecuencia de un rezago del positivismo: la de creer que la pulsión es una cosa que será mejor estudiada mientras más aumento tenga el lente del microscopio con que la analizamos.

\section{LA RECEPCIÓN DE LA IDEA DE PULSIÓN} EN LA FILOSOFÍA Y EN LA TEORÍA DE LAS RELACIONES OBJETALES

La filosofía analítica de la mente del siglo XX se trazó como su principal objetivo destrozar el modelo cartesiano de subjetividad. Este modelo, que planteaba que mente y materia eran dos realidades ontológicas distintas, unidas misteriosamente por la glándula pineal, pareció encontrar un nuevo impulso en la doctrina freudiana de las pulsiones. Por lo menos así lo vieron algunos filósofos interesados en la mente.

Si bien es cierto que hacia 1921 Bertrand Russell (1921) acogió de modo positivo al psicoanálisis y desarrolló una teoría sobre el deseo fuertemente influida por las ideas de Freud, Wittgenstein (1951), y especialmente Gilbert Ryle (1949), en cambio dirigieron sus baterías contra teorías que, sino espe- 
cíficamente freudianas, compartían un espíritu freudiano. Wittgenstein y Ryle, en efecto, repudiaron repetidamente la idea de que un deseo es un "algo" psíquico que antecede y que causa la conducta. Ellos cuestionan que motivación -y por lo tanto todo lo que se suele asociar con los motivos de la conducta, como los impulsos y los deseos- y conducta son realidades separadas que se vinculan causalmente.

Desde una escuela que no es la filosofía analítica, otro filósofo que criticó la concepción biologista de la pulsión es Jurgen Habermas (1982), importante porque discute los dos argumentos más usados por quienes sostienen que el instinto es sobre todo biológico. A saber, la "intensidad" con que una persona experimenta un impulso y lo que en psicoanálisis se llama compulsión a la repetición. Habermas dice que la ilusión de motivos o impulsos de naturaleza biológica en la conducta humana surge del hecho de que los deseos inconscientes reprimidos actúan como una fuerza externa a la conciencia, que los hace aparecer incontrolables. Pero esta, dice Habermas (1982) usando una expresión de Hegel, no es la causalidad de la naturaleza sino del destino. No puede negarse, dice, que las tendencias libidinales y agresivas existen pero estas tendencias no son otra cosas que motivos de acción, es decir intenciones plenamente formadas y lingüísticamente interpretadas, a las que los mecanismos de defensa han negado el acceso a la conciencia.
Para Habermas es necesaria una teoría psicoanalítica del instinto pero sin olvidar que el concepto de instinto, aun cuando se aplica a los animales, es un concepto que se origina en la interacción humana. Hambre, deseo y odio son palabras y conceptos que provienen de estas interacciones y por lo tanto tratar de ofrecer una explicación "cientificista" o positivista de ellos es una empresa condenada al fracaso.

Hay, sin embargo, quienes han mirado con simpatía la división que hace Freud de lo humano en lo que he llamado los dos mundos, como el filósofo Paul Ricoeur (1970), quien nos conmina a no abandonar las hipótesis económicas del psicoanálisis; es decir, las hipótesis que enfatizan el carácter biológico del instinto y a combinar el lenguaje de la "fuerza" (i.e de la energía psíquica) con el lenguaje de la interpretación (i.e el lenguaje del significado de la conducta). Al afirmar que "[...] no podemos reducir los afectos ni su factor cuantitativo a las ideas, ni podemos tratarlos (a los afectos y sus factores cuantitativos) como una realidad distinta de las ideas", Ricoeur enfatiza que el psicoanálisis es único dentro de las disciplinas que procuran una comprensión científica del ser humano porque su razón de ser es la combinación del discurso cuantitativo con el discurso hermenéutico. El instinto, para Ricoeur en su lectura de Freud, es una representación psíquica que se sitúa en el límite entre lo orgánico y lo psíquico. 
Así como en la filosofía, también dentro del movimiento psicoanalítico el campo está dividido entre quienes entienden la idea de instinto desde una perspectiva más fenomenológica o teleológica, y quienes insisten en buscar la esencia del instinto en lo corporal. Es en la escuela de la teoría de las relaciones objetales donde uno encuentra uno de los esfuerzos más creativos para eliminar del concepto de pulsión todo remanente biológico.

Hans Loewald, quien en su trabajo "On motivation and instinct theory" (1971) asume la tarea de discutir los textos freudianos de la pulsión, concluye que debemos olvidarnos de una noción biologista de energía psíquica y de instinto y aceptar que la única versión de pulsión con la que el psicoanálisis debe trabajar es aquella en la que Freud afirma el carácter psicológico, mental y no biológico de la pulsión. Un instinto, dice Loewald, no es algo que actúe desde afuera de la mente. Al hablar de instintos estamos más bien ante modos de conducta que la persona, urgida quizá por presiones del cuerpo, ha desarrollado en su contacto con los demás. Leyendo así a Freud, dice Loewald, concluimos que cualquier pretensión de declarar la existencia de un incognoscible remanente biológico en la pulsión es un error. “¿Cuál es la situación de los instintos en la relación a la organización total del aparato psíquico?", se pregunta Loewald. Él dice que Freud permaneció indeciso toda su vida en cuanto a la naturaleza de los instintos. A veces los concebía como fuerzas psicológicas exentas de toda connotación biológica y etológica y otras veces pareció ceder a la tentación biologizante. Loewald, en cambio, es enfático en señalar la naturaleza psicológica, esto es mental de los instintos. Los estímulos que provienen del cuerpo y del entorno estimulan a la mente a representar. Pero esta función representativa está siempre dentro de lo mental y de lo psicológico. Mientras que los estímulos orgánicos "alcanzan a la mente", afirma Loewald, "los instintos no son los estímulos en sí, pero representan estos estímulos". Afirma también, en una aseveración que es medular para esta monografía, que los instintos se crean en la interacción de la madre con el niño. En una afirmación que sorprendentemente acerca su teoría de la pulsión a la teoría del deseo que Bertrand Russell formuló cincuenta años antes afirma: "Hablando en términos de la ontogénesis de la realidad psíquica, yo quisiera decir que la demandas y urgencias incoherentes del neonato y sus respuestas reflejas devienen organizadas y coordinadas como instintos y asumen metas y dirección a través de sus actividades y las respuestas del ambiente" (Loewald, 1971, p. 119, traducción del autor).

Los instintos, entonces, de acuerdo con Loewald, son creaciones producto de la interacción del bebé con la madre. Una posición muy similar es la de Otto Kernberg (2004), quien ofrece una teo- 
ría sobre la ontogénesis de la pulsión cuyos detalles no podemos tocar en este trabajo. Baste decir que de un modo imaginativo Kernberg postula que las pulsiones son constituidas en la interacción de la madre con el niño. Y aunque Kernberg parece darle al cuerpo -a través de los afectos- una mayor relevancia de la que le otorga Loewald, su tesis es esencialmente que la palabra pulsión se refiere a una realidad psicológica intersubjetivamente creada.

\section{CONCLUSIÓN}

Esta excursión a través de las controversias alrededor del concepto de pulsión ha intentado ilustrar el movimiento dialéctico del concepto "pulsión". Como lo he dicho líneas arriba, el tema me parece pertinente porque creo que existe una tendencia dentro de ciertos movimientos psicoanalíticos a mantenerse fijados en el aspecto más mitológico de la teoría de los instintos: aquel que le otorga al cuerpo misteriosamente una inteligibilidad e intencionalidad o que cree que el ser humano en su estado prelingüístico (es decir los infantes de meses) pueden tener los impulsos y deseos que posee un adulto que ha aprendido a hablar.

Mi opinión es, como la de Loewald y de Kernberg, que las pulsiones se aprenden y se desarrollan en la interacción. Y que lo que aprende el niño es a relacionar, incluso de modo prerreflexivo, sus necesidades corporales con el ensamblaje de instrumentos, códigos, costumbres y palabras que comúnmente llamamos "mundo". Y que constituye un error, en el que incurrió Freud, el de atribuir a la pulsión una esencia biológica.

\section{Referencias}

Freud, S. (1915a). Pulsiones y destinos de pulsión. Obras completas. (Traducción: José Echeverry). Buenos Aires: Amorrortu.

Freud, S. (1915b). Lo inconsciente. Obras completas. (Traducción: José Echeverry). Buenos Aires: Amorrortu.

Habermas, J. (1971). Knowledge and human interest. (Traducción: Jeremy J. Shapiro). Boston: Beacon Press.

Kernberg, O. (2004). Contemporary controversies in psychoanalytic theory, techniques and their applications. New Haven: Yale University Press.

Loewald, H. W. (1971). On motivation and instinct theory. Psychoanalytic Study of the Child, 26, 91-128.

Ricoeur, P. (1970). Freud and philosophy: An essay on interpretation. New Haven: Yale University Press.

Russell, B. (1921). The analysis of mind. Nueva York: Routledge University Press. 